\title{
El miedo y la Revolución de $1810^{1}$
}

\section{Fear and the 1810 Revolution}

\author{
Soledad Monteagudo ${ }^{2}$
}

\section{Resumen}

A partir de la definición del miedo como un fenómeno colectivo y político, en este artículo proponemos que el análisis de sus manifestaciones al iniciarse el siglo XIX debe ser incluido como uno de los elementos explicativos de la participación política de la plebe urbana en el proceso revolucionario rioplatense.

Palabras clave: Miedo; Cultura; Política; Iglesia; Revolución

\begin{abstract}
From the definition of fear as a collective and political phenomenon, in this article we propose that the analysis of its manifestations at the beginning of the nineteenth century should be included as one of the explanatory elements of the political participation of the urban plebs in Rio de la Plata revolutionary process.
\end{abstract}

Keywords: Fear; Culture; Politics; Church; Revolution

\section{Introducción}

Las preocupaciones contemporáneas en torno a la seguridad en las grandes ciudades y el miedo a los ataques terroristas que sufrió parte de la civilización occidental desde finales del siglo XX dispararon una gran cantidad de trabajos de cientistas sociales vinculados a la sensación de inseguridad, al miedo colectivo y al rol de las instituciones políticas y de los medios de comunicación en su creación, difusión y magnificación. La Historia, sin embargo, ha contribuido muy poco a esta discusión.

A los estudios pioneros de Lefebvre (1986), Carlé (1991) y Delumeau (2002 a y b), han seguido más recientemente los de Gonzalbo Aizpuru (2009), Speckman (2009) y Rosas Lauro (2005) y algunos esfuerzos aislados por parte de jóvenes investigadores en torno al miedo

\footnotetext{
${ }^{1}$ Trabajo recibido el 16/09/2019. Aceptado el 28/11/2019.

${ }^{2}$ Universidad de Morón. Contacto: soledad_monteagudo@hotmail.com
} 
político en el Medioevo español (Villarroel González, 2013; Foronda, 2007). Sin embargo, para el caso que nos ocupa, el del Rio de la Plata, no ha sido posible encontrar ningún estudio al respecto. Aunque Delumeau (2002a) considera que esta falencia se debe a una larga tradición de identificación entre el miedo y la cobardía, creo que el escaso interés que ha despertado esta cuestión se debe a deficiencias en el enfoque metodológico utilizado, que abre escasas perspectivas de análisis. Como sostiene Rosas Moscoso «el tratamiento periférico del miedo podría implicar una fragilidad en las relaciones interdisciplinarias, en especial en los necesarios vínculos entre la Historia y la Psicología» (Rosas Lauro, 2005). A lo que habría que agregar los aportes que al respecto han realizado los antropólogos y sociólogos, que nos permiten acceder a un enfoque cultural de las emociones y sobre todo del miedo, del que carecen la mayoría de los trabajos que reducen el análisis a una detallada enumeración de los miedos «perpetuos» o «coyunturales» de la sociedad, sin avanzar en las implicancias sociales, políticas y culturales que tienen en ella y de las que son fruto.

El miedo es básicamente una reacción que el hombre comparte con el animal y que desencadena una sucesión de procesos fisiológicos. En su expresión individual, es una emoción choque que se produce ante la toma de conciencia de la existencia de un riesgo o peligro que amenaza nuestra subsistencia. Sin embargo, como sostiene Le Breton (2009), las emociones se arraigan en una «cultura afectiva» que provee «esquemas de experiencia y acción sobre los cuales el individuo entreteje luego su conducta y reflexión» (p. 10). De este modo, el miedo no es una manifestación individual sino cultural y, por tanto, colectiva.

El miedo, además, puede ser político cuando se trata de un miedo que emana de la sociedad y tiene repercusiones dentro de ella, por ejemplo, en el dictado y aplicación de políticas públicas, en el ascenso o caída de algunos grupos del poder, en la creación o derogación de leyes (Robin, 2009). Por todo lo enunciado hasta aquí, podemos señalar que el miedo es una construcción social y cultural y que, por lo tanto, puede ser aprendido, enseñado, amplificado y manipulado.

En el contexto del proceso revolucionario iniciado en el Río de la Plata en 1810 sostenemos que el miedo colectivo debe ser incluido como uno de los elementos explicativos de la participación política de la plebe urbana. Aunque obviamente no se trató del único factor, el análisis de los sucesos por los que atravesó la plebe de Buenos Aires desde fines del siglo XVIII contribuye a amplificar el sentimiento de ansiedad colectiva 
que se evidencia en las fuentes y que puede explicar en parte su accionar.

El período bajo estudio es prolífico en la elaboración de escritos públicos de todo tipo (sermones, proclamas, catecismos, pasquines y diarios) que nos permitirán acceder a las expresiones colectivas respecto del miedo. En este estadio de la investigación nos proponemos el análisis de fuentes editas que fueron producidas por dos instituciones de importancia fundamental a la hora de construir y propalar el miedo: el Cabildo y la Iglesia.

Aunque se trata de documentos con una difusión e impacto social desigual, puesto que no todos fueron producidos para impactar en la esfera pública, ${ }^{3}$ su importancia radica en la existencia de ciertos marcadores lingüísticos que, conjugados con las prácticas que ahí mismo se enuncian, instauran y fortalecen un miedo colectivo que buscó funcionar como un ordenador de conductas. En definitiva, intentaremos, como sostiene Darnton (2009), entender el «sentido de los documentos relacionándolos con el mundo circundante de los significados, pasando del texto al contexto, y regresando de nuevo a éste para lograr encontrar una ruta en un mundo mental extraño» (p.13).

Con el objeto de dar cuenta de este proceso, en un primer apartado analizaremos la construcción de los miedos colectivos sobre la base de los discursos de su principal difusor y controlador, la Iglesia. En un segundo apartado analizaremos el modo en que esos miedos entraron en escena en el contexto revolucionario, a partir del análisis de algunos acuerdos del Cabildo de Buenos Aires que nos permiten acercarnos a los temores que experimentaba la población y su elite dirigente.

\section{La religión y la enseñanza del miedo}

Lo que llamamos «enseñanza del miedo» llegó al Río de la Plata de la mano de uno de sus constructores clásicos: la religión católica. En tanto educadora, la Iglesia sirvió desde la conquista como «constructora» o reforzadora de miedos, algunos de reciente aparición y otros arraigados en la idiosincrasia y el imaginario desde tiempo atrás. Además, es necesario recordar que, en el período estudiado, las esferas eclesial y

\footnotetext{
${ }^{3}$ Fundamentalmente, el trabajo utiliza dos tipos de fuentes, algunas producidas para ser ampliamente difundidas, como el Tratado que reproducimos para la enseñanza en las escuelas o el novenario a Santa María; mientras que otras, como las acordadas del Cabildo, fueron solo muy parcialmente conocidas.
} 
estatal no se encuentran divididas (cf. Di Stefano, 2004), sino que juntas entretejen los discursos, las representaciones y las prácticas colectivas, por lo cual la legitimidad política descansa en gran medida en la pedagogía que la religión impone.

A lo largo de la Historia, las distintas religiones han tenido una enorme autoridad basada en su supuesta capacidad de interpretar signos emitidos por la divinidad y, a partir de ellos, dictar conductas que resultaban aceptables para esta. En el caso de la religión católica, el fundamento doctrinario parte de un pecado cometido por el hombre. Ese pecado original cometido por Adán a instancias de Eva marcó para siempre a la Humanidad y convirtió al hombre en un ser que busca, a lo largo de su vida, por medio de acciones y oraciones, la expiación de ese pecado. Debido a esa falta primigenia es que los cristianos creen que se encuentran permanentemente expuestos a un castigo (Cf. Delumeau, 2002 a y b; Robin, 2009; Gonzalbo Aizpuru, 2009).

La existencia de ese pecado original transformó el miedo a la muerte en el miedo al purgatorio. En un «Tratado de las obligaciones del hombre» adoptado por el Cabildo en 1816 para la enseñanza en escuelas de la capital de las Provincias Unidas del Río de la Plata, puede leerse que «el Señor es juez rigurosísimo de los transgresores de sus leyes, y castiga con penas terribles en esta vida, y en la otra al que se atreve a quebrantarlas»(Maillé, 1967, p. 11). En una novena que se hacía en la época a Santa María se argumenta que «no hay pena más lastimosa que la que padecen las almas en el Purgatorio», para lo cual se solicita la intervención de la madre de Dios, cuyo accionar «templa el fuego en que se abrazan aquellos afligidos espíritus» (Maillé, 1967,p. 225). Llamas eternas, el encuentro con el Maligno que es figurado como una «bestia sangrienta», son sin duda, imágenes que aterrorizaban al conjunto de la población. Es lógico por ello que en las oraciones se sostuviera que «mucho me temo en la vida, pero más me recelo en la muerte»(Maillé, 1967, p.217).

Pero el Dios de la sociedad rioplatense no se limita a castigar las faltas cometidas en la otra vida,muchas veces castiga los pecados cometidos también en esta. La enfermedad, la pobreza, y la falta de honor entre otras muchas tribulaciones de la época aparecen ligadas a la noción de pecadoy es por eso por lo que los hombres que atraviesan dichos trances se sienten obligados a practicar acciones de expiación.

Los pecados -y los castigos que Dios envía para purgarlos- tampoco afectan solo a los individuos, muchas veces la conducta «desviada» 
de alguno de los miembros de la comunidad, lleva al castigo colectivo. Ante esas situaciones -que podían evidenciarse en epidemias, malas cosechas, invasioneso cualquier otro flagelo colectivo- el pedido de auxilio a la divinidad permitía no sólo conjurar el temor sino, también, reconstruir el tejido social que podía romperse por el miedo a los sufrimientos. Ejemplo de ello fue el hecho de que, ante una feroz sequía experimentada en Buenos Aires entre 1802 y 1804, el Cabildo ordena procesiones y rogativas. En otra oportunidad, con motivo de la inminencia de la segunda invasión inglesa en 1807, el Cabildo apunta que «se leio un oficio del Ilustrisimo Señor Obispo, en que indica la protección que en las actuales apuradas circunstancias debemos implorar del Dios de los exercitos con rogaciones públicas». ${ }^{4}$

A partir de la noción de pecado y del temor al purgatorio, la Iglesia construyó miedos y normas que implicaban comportamientos aceptados y sancionados y cuya violación implicaba un castigo no solo individual, sino también colectivo.

Paralelamente, en estos años la necesidad de afirmación por parte del estado colonial llevó a la proliferación de discursos en torno a la necesidad de obediencia y a las calamidades pasibles de acontecer en caso de insubordinación. Si bien en todas las sociedades la legitimación en el ejercicio del poder se logra por medio de la capacidad estatal para mantener el orden y resolver los conflictos, siempre subyace en ellas la creencia en la existencia de un caos primigenio que fue dominado por una forma de gobierno fuerte. Lo antedicho constituye el fundamento de la teoría que Hobbes desarrolló sobre el Estado.

Sin embargo, existe una arista del pensamiento hobbesiano que se vincula directamente con nuestra hipótesis y que no ha sido lo suficientemente remarcada. El miedo que haría que racionalmente los hombres decidieran ceder parte de su libertad en el Leviatán es un miedo creado, no una pasión primitiva que estaba latente para ser explotada por el soberano. Hobbes dedica largos párrafos a explicar que los hombres influyentes, las universidades y la Iglesia deben inculcar el miedo a la muerte en la población. Es decir, deben dedicarse a desterrar del imaginario colectivo las resistencias frente a la muerte, que se habían basado en las ideas de honor y de gloria. En su razonamiento, una vez iniciado el pro-

${ }^{4}$ Archivo General de la Nación. (1930). Acuerdos del extinguido cabildo de Buenos Aires. Serie IV, p. 567. Buenos Aires, Argentina: Kraft. 
ceso de convencimiento del valor de la vida, será el boca a boca el que lo difunda al conjunto de la sociedad.

Efectivamente, la Iglesia ha sido en el Rio de la Plata, portadora y difusora de este mensaje que permitía fundamentar la sujeción. En una carta pastoral de la época puede leerse que:

la sociedad, después de la confusión que el pecado há introducido en el mundo, sería un verdadero caos, si en ella no se hubiese establecido esa recíproca y estrecha relación entre los que mandan, y los que obedecen; esa firme y hermosa cadena, cuios eslabones no pueden separarse unos de otros sin destruirse mutuamente (Maillé, 1967, p. 282)

El arzobispo exhorta a sus fieles a asemejarse a los primeros apóstoles cristianos «como ellos debemos permanecer sujetos muy de corazón a las potestades legítimas, sin que nadie, (...) pretenda eximirse de un precepto que comprende á todos» (Maillé, 1967, p. 290). La legitimación del orden vigente que ha sido una de las prerrogativas de la Iglesia católica desde antaño se justifica aquí por el peligro que representa para el entramado social cualquier alteración del orden. Sumisión y virtud, desobediencia y pecado representan nociones básicas que todo buen súbdito debe interiorizar.

La Iglesia, en tanto ordenadora de conductas, establece los comportamientos sociales aceptables, fundamenta la legitimidad del poder político y sanciona las desviaciones a las normas utilizando el pecado, el purgatorio y el paraíso y las emociones que estas tres nociones despiertan en los fieles. Cuando la Revolución se produzca, la inexistencia de una condena unánime por parte de los párrocos será sin duda un factor significativo en la posibilidad de crear un nuevo ordenamiento social.

\section{El miedo y la revolución}

Pensado desde esta perspectiva, el análisis de los miedos que sacudieron a la sociedad porteña durante la década prerrevolucionaria puede contribuir a explicar el accionar de la plebe porteña y a echar luz sobre las decisiones que los actores tomaron en ese contexto.

La coyuntura era definitivamente explosiva. Durante el decenio que precedió a la revolución de 1810, Buenos Aires enfrentó dos invasiones inglesas y un aumento desmedido de la población esclava, que era 
percibido como una amenaza al orden establecido. Además, la inestable situación económica acrecentaba los temores. A un largo período de sequía y aumento de precios del trigo y de la carne, siguió un aumento en la carga impositiva originada tanto en la necesidad de auxiliar a la metrópoli como en la de mantener a las milicias porteñas encargadas de proteger a la ciudad ante una posible invasión extranjera. Analicemos el impacto de cada uno de ellos.

Entre 1802 y 1804, la ciudad de Buenos Aires y su campaña fueron asoladas por una larga sequía, que puso en entredicho no solo el abasto de carne de la ciudad, sino también a la salud de la población. En efecto, aunque la pobreza era una constante en los arrabales de la ciudad, la abundante cantidad de carne había permitido consumir una dieta relativamente alta en proteínas incluso a los sectores marginales. La prolongada sequía puso en jaque el abasto de la ciudad con lo que el cabildo expresó su miedo de que «un solo día sin este producto en la plaza produciría consecuencias fatales porque es un alimento universal y habitual de todas las clases»(Johnson, 2013,p. 245). En forma simultánea, la sequía ocasionó un aumento significativo en el precio del trigo entre 1802 y 1804.

La única respuesta que el Cabildo ensaya en este lúgubre contexto evidencia la persistencia de comportamientos supersticiosos frente a aquello a lo que no se tiene respuesta: para poner fin al malsugiere que «se ocurra á implorar el auxilio divino por medio de nuestro Santo Patron el Señor San Martin, haciendo un novenario de misas cantadas delSacramento en la Santa Yglesia Catedral». ${ }^{5}$

Al miedo a la muerte por la falta de comida o por las enfermedades propias del calor y la mala alimentación, el Cabildo agrega el sufrimiento por el miedo al castigo divino. Los atronadores relatos desde los púlpitos enfatizaban esta situación. La certeza con que los sacerdotes cargaban en el pecado colectivo la causa de la sequía, aumentaba el miedo social.

En forma coincidente y consecuente con la sequía que azotaba a la región, desde fines de 1802 y durante el verano de 1803, BuenosAires padeció una «peste tan perniciosa» cuyos principales síntomas eran una «fiebre pútrida con llagas á la garganta». ${ }^{6} \mathrm{El} 10$ de diciembre de 1802,

5 Archivo General de la Nación. (1930). Acuerdos del extinguido cabildo de Buenos Aires. Serie IV, pp. 102-103. Buenos Aires, Argentina: Kraft.

${ }^{6}$ Archivo General de la Nación. (1930). Acuerdos del extinguido cabildo de Buenos Aires. Serie IV, p. 184. Buenos Aires, Argentina: Kraft. 
apenas 10 días después de documentado el primer brote de peste, y ante la solicitud del Síndico para que se tomen medidas de higiene pública, el Cabildo ordena que

se renueven las ordenes antiguas, sobre que los Lotes, ó Partidas de negros bozales se depositen y alogen en los extremos de la Ciudad, á fin de que los mercaderes introductores de negros los acomoden para que si tuviesen que hacerlos bañar, lo practiquen en el rio por aquella parte, donde no hay temor que infesten con sus malos humores el agua, por ser rio abajo ${ }^{7}$

Aquí, el miedo a que laepidemia fuera causada por los «malos humores» con que los negros infestan el aguase anuda con un temor ancestral: el miedo al otro. Huelga decir que a lo largo de la Historia sobran los ejemplos de persecuciones a judíosacusados de contaminar los pozos de agua, a extranjeros que se creía traían las epidemias en los barcos e incluso a las mujeres, a las que se acusaba de actos de brujería que enfermaban a la población. La sociedad rioplatense decimonónica no estaba exenta de estos miedos.

En este caso, el otro es el negro. Por supuesto, esto tiene una explicación vinculada con la cantidad de africanos esclavos que había en la colonia y lo «repentino» de su aparición.Hasta 1776, los comerciantes esclavistas transfirieron la mayor parte de los esclavos importados a otros lugares en el interior de lo que luego sería el virreinato del Río de la Plata. A partir de 1780, la cantidad de esclavos que permanecían en Buenos Aires, consecuencia del nuevo rango de capital virreinal y de las mayores oportunidades de empleo, aumentó en forma sostenida.

Este aumento de la población esclava impacta en una época de inestabilidad económica.Tras la expansión de que se había beneficiado la ciudad después de 1770, en la década del noventa las condiciones parecían haber cambiado. Como demuestra Johnson (2013), este fue un período de precios en alza, de suba de la tasa de mortalidad, de perturbaciones en el comercio atlántico y de una caída en el salario real debida a la competencia de una población esclava creciente. Según el autor «hacia 1795, las autoridades coloniales percibieron que una iracunda plebe estaba predispuesta a la confrontación y era potencialmente susceptible a los seductores argumentos de los agentes revolucionarios» (p. 205).

${ }^{7}$ Archivo General de la Nación. (1930). Acuerdos del extinguido cabildo de Buenos Aires. Serie IV, p. 184. Buenos Aires, Argentina: Kraft. 
Esta situación de recesión económica e inestabilidad social se vio agudizada a raíz del aumento de la presión fiscal, consecuencia primero de la militarización que siguió a las invasiones inglesas y luego producto de las urgencias de la monarquía.La defensa de la ciudad frente a las invasiones implicaba un enorme costo para las arcas públicas, pues el sueldo que se abonaba a las milicias era particularmente gravoso para ellas. Como sostiene Halperin Donghi (1978) «la profesionalización de regimientos enteros creó la necesidad de nuevos ingresos del orden de un millón de pesos al año» (p. 134). En 1809, Mariano Moreno, futuro secretario de la Junta revolucionaria, escribía al virrey que «las tropas no pueden ser sostenidas sin ingentes sumas que deben invertirse en su subsistencia, y este es un gasto tan urgente como indispensable su continuación» (Halperin Donghi, 1978, p. 134). Los sueldos de los milicianos contribuyen a explicar su participación en varios episodios de estos años en los que actuaronen defensade sus nuevos puestos de trabajo y de sus comandantes. La milicia constituyó una salida laboral fundamental para la plebe en una época inestable económicamente y, a partir de 1809, el accionar del virrey puso en riesgo su continuidad. ${ }^{8}$

La necesidad de aumentar la recaudación llevó a la creación de nuevos impuestos y contribuciones. Unos meses después, sin embargo, el 6 de octubre de 1808, el entonces virrey Liniers se ve forzado a suspender «el impuesto que se há señalado sobre la Carne como uno de los arbitrios tomados para ocurrir á las urgencias del Erario» debido a que éste «se hace mas sensible á la gente pobre, que me deve toda consideración, no menos que sobre las Tropas». ${ }^{9}$ Evidentemente, los clamores de los pobres y la presión de la tropa obligaron al virrey a retrotraer su impopular medida.

Sin embargo, a partir de entonces, las quejas de los recaudadores son recurrentes por el notorio incremento de la evasión fiscal por parte de los contribuyentes. En 1809, el recaudador de un nuevo impuesto ${ }^{10}$ comunica al cabildo «no serle posible recaudar esas cantidades por que

\footnotetext{
${ }^{8}$ Johnson (2013) señala que a la llegada del virrey Cisneros los costos militares superaban los recursos fiscales por lo que éste intentó la reducción de la cantidad de los batallones de milicias que recibían un salario completo, lo que generó suspicacia e inquietud entre los miembros de la plebe armada.

9 Archivo General de la Nación. (1930). Acuerdos del extinguido cabildo de Buenos Aires. Serie IV, p. 258. Buenos Aires, Argentina: Kraft.

${ }^{10}$ Respecto del incremento de las obligaciones fiscales y la situación de larecaudación véase Ensink (1990) y Galarza (2017).
} 
se acogen á mil escusas y pretextos, y aun repugnan el pago». Los cabildantes manifiestan, por su parte, ser ya «intolerable este comportamiento de los deudores, pues que no han bastado, ni los medios de rigor, ni los de prudencia, quando por otra parte son gravísimas las urgencias, y la caxa se halla sin fondos». ${ }^{11}$ Evidentemente, la irritación del cabildo se debe a que esta conducta no era nueva y se agudizaba en la medida en que también lo hacían las urgencias del erario.

La difícil situación por la que atravesaba el erario agravada por la rebelión en curso en el Alto Perú, que hacía temer una interrupción en los ya menguados envíos metálicos de ese origen forzó al nuevo virrey, Cisneros, a permitir la entrada de barcos de bandera británica en el puerto de Buenos Aires. Según Johnson (2013) esta situación afectó terriblemente a las manufacturas y artesanías de la ciudad «el primer barco británico que legítimamente pudo descargar mercadería trajo diecinueve mil pares de zapatos de confección inglesa. De esta forma, quedó destruido un año de demanda de zapatos comunes, los mismos que utilizaba la plebe» (p. 24). Si bien probablemente la plebe se benefició de los precios más bajos de los productos británicos, los sectores artesanos, sobre todo los de más alto rango entre ellos, resultaron sumamente perjudicados.

En tanto, los ingresos de las arcas públicas no mejoraban. En vísperas de la revolución, el 11 de mayo de 1810 el tesorero de propios y arbitrios plantea un lúgubre panorama. «Desde primero de Enero hasta diez y siete de Abril de este año solo entraron en la Tesoreria de su cargo trece mil nuevecientos cincuenta y cinco pesos quatro y medio reales por derecho del nuevo impuesto (...)». No solo es poco lo recaudado, sino que «hace un mes no se recibe nada en la Tesoreria por este respecto». ${ }^{12}$ Resulta sugestivo que en una carta pastoral escrita por el Arzobispo de La Plata en febrero de 1809 se recuerde a los feligreses que los primeros apóstoles pagaban con «puntualidad los tributos y demás pechos concejiles, y como en lugar de defraudarlos con maliciosos pretextos sacaban del trabajo de sus manos y del sudor de su rostro el producto o caudal necesario para satisfacer tan justa carga»(Maille, 1967, p. 287). Moxó llega incluso a recurrir a la figura del mismo hijo de Dios para justificar

\footnotetext{
${ }^{11}$ Archivo General de la Nación. (1930). Acuerdos del extinguido cabildo de Buenos Aires. Serie IV, p. 573. Buenos Aires, Argentina: Kraft.

${ }^{12}$ Archivo General de la Nación. (1930). Acuerdos del extinguido cabildo de Buenos Aires. Serie IV, p. 104. Buenos Aires, Argentina: Kraft.
} 
sus dichos, así sostiene que Jesús «pagó tributo, y no teniendo dinero de que echar mano, recurrió á un milagro, antes que dexar de cumplir como ciudadano esta indispensable deuda» (Maillé, 1967, p. 285). ¿No es acaso esto evidencia del temor a una revolución fiscal que terminara de socavar las bases mismas del sistema colonial? ¿Una exhortación a cumplir con los deberes para con un Estado que, sin embargo, se ve cada vez más imposibilitado de cumplir con su contraparte?

A colación de esta situación quiero recordar una frase pronunciada por José Díaz, durante el sumario llevado adelante en su contra por supuesto partícipe en la conspiración de los franceses de 1809. Este correntino empobrecido sostuvo, casi 15 años antes de esta suerte de rebelión fiscal que «el virrey será decapitado porque es un perro ladrón que envía toda nuestra plata a España»(Johnson, 2013, p. 237). Evidentemente, no era el único que lo pensaba.

La necesidad de enviar parte de lo recaudado a la metrópoli es una vieja queja de los criollos, que evidentemente se vio agudizada cuando quedó en evidencia que esas remesas no servían para garantizar la seguridad local. Invariablemente, la incapacidad de las tropas regulares para hacer frente a las invasiones inglesas y el servilismo con el que los demás funcionarios del gobierno, las corporaciones seculares y religiosas la aceptaron, encrespó aun más los ánimos contra la metrópoli. Si la obligación de contribuir al Estado se fundamenta en la necesidad de brindar a éste los recursos necesarios para que ejerza el monopolio de la violencia, y nos provea con ella de seguridad, las deficiencias de la corona en este sentido, que venían sin embargo de larga data, ${ }^{13}$ acabaron por convencer a los rioplatenses de lo innecesario, inconveniente e incluso peligroso de enviar el metálico que era necesario para apuntalar la defensa de la ciudad.

La coyuntura empujó a la plebe a participar en los sucesos políticos para garantizar aquello que sus clases dominantes ya no podían asegurarle: defensa frente al invasor extranjero, el sueldo miliciano, protección frente a los vaivenes económicos. La revolución se constituyó entonces, en una esperanza y una promesa frente a la que, además, el discurso eclesiástico tuvo posturas ambiguas, dejando librado a los sermones de cada párroco la certeza de en qué bando se encontraba el pecado y en cuál la posibilidad de redención.

\footnotetext{
${ }^{13}$ Halperin Donghi (1978) señala que cuando los portugueses abandonaron Colonia del Sacramento en 1777 se permitió un rápido deterioro del sistema de defensa.
} 


\section{Conclusión}

Hemos explorado los «miedos colectivos» partiendo del estudio de su construcción por parte de la Iglesia católica. Hemos señalado que se trata de una sociedad cuyo basamento es el miedo: al infierno, el miedoa Dios y al Rey. La Iglesia, que funcionó como elemento de cohesión y de legitimación política, no dudó en atizar los terrores o en bendecir las acciones más aterradoras con el único objeto de sostener una «dominación suave y feliz»(Maillé, 1967, p. 285). Sin embargo, el contexto revolucionario puso en crisis sus discursos respecto del orden legítimo con lo cual contribuyó a ampliar la brecha que la prisión del rey había abierto.

Además, en el contexto de la primera década del siglo XIX,los miedos colectivos fueron resignificados y se conjugaron a un tiempo creando una situación potencialmente revolucionaria. En el segundo apartado de este trabajo, hemos analizado la situación de inestabilidad económica, política y social que, desde nuestro punto de vista, contribuyó a impulsar la participación popular en la revolución.

Aunque no se trata de ignorar el factor de oportunidad que la pérdida de gran parte de España en manos francesas significó para estos territorios, creemos que nuestro trabajo contribuye a poner en perspectiva aquellos factores que prepararon el terreno local para que la revolución fuera posible.

\section{Referencias bibliográficas}

Carlé, M. (1991). Los miedos medievales (Castilla, siglo XV).Estudios de Historia de España, IV, 109-157.

Darnton, R. (2009). La gran matanza de gatos y otros episodios en la historia de la cultura francesa. Buenos Aires, Argentina: Fondo de Cultura Económica.

Delumeau, J. (2002a). El miedo en Occidente. Madrid, España: Taurus.

Delumeau, J. (2002b). El miedo. Reflexiones sobre su dimensión social y cultural. Medellín, Colombia: Corporación Región.

Di Stefano, R. (2004). El púlpito y la plaza: clero, sociedad y politica de la monarquía católica a la república rosista. Buenos Aires, Argentina: Siglo XXI. 
Ensink, O. (1990). Propios y arbitrios del cabildo de Buenos Aires, 15801821: historia económica de una gran ciudad. Madrid, Instituto de Cooperación Iberoamericana.

Foronda, F. (2007). El miedo al rey. Fuentes y primeras reflexiones acerca de una emoción aristocrática en la Castilla del siglo XIV. e-Spania. Revuesinterdisciplinaired'étudeshispaniquesmédiévales et modernes, 4.http://e-spania.revues.org/2273.

Galarza, A. (2017). Recaudación fiscal, abasto y control del ganado en el Buenos Aires tardocolonial: los propios y arbitrios del cabildo entre 1780 y 1820. América Latina en la historia económica, 24 (2), 7 34.

Gonzalbo Aizpuru (2009). Una historia de los usos del miedo. México, México: El Colegio de México.

Halperin Donghi, T. (1978).El ocaso del orden colonial en Hispanoamérica. Buenos Aires, Argentina: Sudamericana.

Johnson, L. (2013). Los talleres de la revolución. La Buenos Aires plebeya y el mundo Atlántico, 1776-1810. Buenos Aires, Argentina: Prometeo.

Le Breton, D. (2009). Las pasiones ordinarias. Antropología de las emociones. Buenos Aires, Argentina: Nueva Visión.

Lefebvre, G. (1986). El gran pánico de 1789. Barcelona, España: Paidós.

Maillé, A. (Comp). (1967). La revolución de Mayo a través de los impresos de la época. Buenos Aires, Argentina: Comisión Nacional Ejecutiva del $150^{\circ}$ aniversario de la Revolución de Mayo.

Speckman Guerra, E. (2009). Los miedos en la Historia. México, México: El Colegio de México.

Robin, C. (2009). El miedo. Historia de una idea politica. México, México: Fondo de Cultura Económica.

Rosas Lauro, C. (Ed.). (2005). El miedo en el Perú. Siglos XVI al XX. Lima, Perú: Pontificia Universidad Católica del Perú.

Villarroel González, O. (2013). Imponer el miedo en la política bajomedieval castellana. España medieval, 36, 61-78. 